\title{
Spectroscopic Comparison of 4-Isopropyl-N, N-Bis (4-Azidophenyl) Aniline molecule (IPAPA): DFT and MEP Analysis
}

\author{
Ertugrul CIFTCI ${ }^{1}$, Ahmet Cagri ATA ${ }^{1 *}$, Ümit YILDIKO² ${ }^{2}$ İsmail CAKMAK ${ }^{1}$
}

\begin{abstract}
Nuclear magnetic resonance, vibrational, structural and electronic properties for 4isopropyl-N, N-Bis (4-azidophenyl) aniline (IPAPA) were determined by quantum chemical calculations of the DFT method. The results were compared with experimental ${ }^{1} \mathrm{H}-\mathrm{NMR}$ spectral data. Theoretical chemical calculations and experimental values were in harmony. The band gap of HOMO - LUMO indicates that the IPAPA molecule is chemically active and has charge transfer in the monomer. In addition, molecular electrostatic potential (MEPS) maps were drawn to identify the reactive regions of the IPAPA molecule. Hybrid functional B3LYP and hybrid exchange-correlation functional named CAM-B3LYP methods of density functional theory (DFT) were selected as the study method. In both methods, molecular optimization and electronic properties were obtained by using 6-311 ++ G (d, p) base set. In addition, HOMO and LUMO energies have been used to identify spherical reactivity and to determine chemical stability.
\end{abstract}

Keywords: Triphenyl Amine, DFT, HOMO-LUMO, MEPS.

\section{4-İzopropil-N, N-Bis (4-Azidofenil) Anilin molekülünün (IPAPA) Spektroskopik Karşılaştırması: DFT ve MEP Analizi}

ÖZET: 4-izopropil-N,N-Bis (4-Azidofenil) Anilin (IPAPA) için nükleer manyetik rezonans, titreşimsel, yapısal ve elektronik özellikler DFT yönteminin kuantum kimyasal hesaplamaları ile belirlenmiştir. Sonuçlar deneysel ${ }^{1} \mathrm{H}-\mathrm{NMR}$ spektral verileri ile karşılaştırıldı. Teorik kimyasal hesaplamalar ve deneysel değerler uyum içindeydi. HOMO ve LUMO'nun bant boşluğu, IPAPA molekülünün kimyasal olarak aktif olduğunu ve monomerde yük transferine sahip olduğunu gösterir. Ek olarak, moleküler elektrostatik potansiyel (MEPS) haritaları IPAPA molekülünün reaktif bölgelerini tanımlamak için çizildi. Yoğunluk fonksiyonel teorisinin (DFT), CAM-B3LYP metotları olarak adlandırılan hibrid fonksiyonel B3LYP ve hibrid değişim-korelasyon fonksiyonu çalışma yöntemi olarak seçilmiştir. Her iki yöntemde de, moleküler optimizasyon ve elektronik özellikler 6-311 ++ G (d, p) baz seti kullanılarak elde edildi. Ek olarak, HOMO ve LUMO enerjileri küresel reaktiviteyi tanımlamak ve kimyasal kararlılığı belirlemek için kullanılmıştır.

Anahtar kelimeler: Trifenil Amin, DFT, HOMO-LUMO, MEPS.

\footnotetext{
${ }^{1}$ Ertuğrul CIFTCI (Orcid ID: 0000-0001-5866-8597), Ahmet Cagri ATA (Orcid ID: 0000-0002-2296-2265), İsmail CAKMAK (Orcid ID: 0000-0002-3191-7570), Kafkas Üniversitesi, Fen-Edebiyat Fakültesi, Kimya Bölümü, Kars, Türkiye ${ }^{2}$ Ümit YILDIKO (Orcid ID: 0000-0001-8627-9038), Kafkas Üniversitesi, Mühendislik-Mimarlık Fakültesi, Biyomühendislik Bölümü, Kars, Türkiye

*Sorumlu Yazar/Corresponding Author: Ahmet Çağrı ATA, e-mail: ahmetata1024@gmail.com
}

Geliş tarihi / Received: 11-02-2020

Kabul tarihi / Accepted: 28-04-2020 


\section{INTRODUCTION}

Triphenylamine (TPA) derivatives have attracted great attention due to their electroactive properties and potential applications such as hall carriers, light emitters and photoconductors. TPA derivatives are electroactive conductive materials with an easily oxidizable electroactive core and excellent hall carrying capacity (Duan et al., 2019; Yadav et al., 2020). Therefore, the investigation of the electrochemical process of TPA based materials is a very important category. The triphenylamine derivatives, which are rich in electrons, are one of the promising donor parts of the donor-acceptor species of functional molecules because of their good electron-donating and high-hall carrier properties (Gu et al., 2009; Steponaitis et al., 2019). Triphenylamine derivatives are important molecules in numerous dye-sensitive solar cells due to the unique irregularity of the three phenyl substituents, the strong electronizing agent, the high light-to-electric conversion efficiency and good hall carrying capacity, and organic electroluminescence materials(Sęk et al., 2019; Yoosuf et al., 2019). Properties of triphenylamine-based derivatives were investigated using absorption, fluorescence spectroscopy, thermogravimetric analysis and density functional theory calculations (Bourass et al., 2019; Priyatha et al., 2019; Qian et al., 2017; Weng et al., 2016).

Nowadays, the theoretical calculation methods used are easily applied in the laboratory environment for non-synthesized or non-synthesized molecules and the desired results can be obtained. Computational chemistry is a branch of chemistry where computers are used as an aid in solving chemical problems (Boyd, 2019). In computational chemistry, effective computer programs are used to calculate structures, molecules and solid properties. Some theoretical computational studies provide more accurate results than experimental methods. The results of the studies performed by calculation methods are very reliable (Gu et al., 2009; Priyatha et al., 2019; Yadav et al., 2019).

In this study, 4-isopropyl-N, N-Bis (4-Azidophenyl) aniline (IPAPA) molecule synthesized by our group was first drawn with Gauss View 6.0 and the input file was created. The ab-initio calculations were performed in Gaussian 09 package program. Hybrid functional B3LYP and hybrid exchange-correlation functional named CAM-B3LYP methods of density functional theory (DFT) were selected as the study method. In both methods, molecular optimization and electronic properties were obtained by using 6$311++\mathrm{G}(\mathrm{d}, \mathrm{p})$ base set. The ${ }^{1} \mathrm{H}-\mathrm{NMR}$ spectrum of the molecule was compared with theoretical calculations and experimental results.

\section{MATERIALS AND METHODS}

Theoretical analysis of ${ }^{1} \mathrm{H}-\mathrm{NMR}$ spectra of some triphenyl amine derivative was performed by using Chem Office and Gaussian 09 programs (M. J. Frisch, 2016). IPAPA molecule was first drawn in the ChemBioDraw program for molecule for ab-initio calculations made in the Gaussian 09 program and minimized by the Chem3D program by SYBL2 (mol2). Minimized molecules were given to Gaussian 09 program and ab-initio calculations were made for the structure.

For molecule, the gas phase was first optimized using the base set of B3LYP 6-311G ++ G (d, p). Then, for molecule, both the gas phase CAM-B3LYP 6-311 G++ $(\mathrm{d}, \mathrm{p})$ optimization and freq calculation was performed. The ${ }^{1} \mathrm{H}-\mathrm{NMR}$ spectra of the molecule were compared with the experimental results by theoretical calculations.

\section{RESULTS AND DISCUSSION}

\section{Geometry Optimization}

IPAPA optimized basic state structure and total energy conversion are given in Figure 1. DFTB3LYP / CAM-B3LYP - 6-311 G++ (d, p) optimized bond lengths, bond angles and dihedral angles 
parameters of the calculated molecule are listed in Tables 1 and 2. All the values calculated theoretically from the optimized geometry of IPAPA molecule were given and compared in Figure 2-3. This means that the structure has the minimum potential energy. All bond lengths and bond angles in the phenyl rings are within the normal range.

C-C bond distances of 1.08363-1.53993 $\AA$ for DFT and 1.08310 - 1.53209 $\AA$ for CAM-B3LYP, 1.41818-1.41983 $\AA$ for DFT and 1.41386 - 1.41855 $\AA$ for CAM-B3LYP belong to the nitrogen atom bound to the phenyl ring. The $\mathrm{C}-\mathrm{H}$ lengths in the aromatic ring are 1.08322-1.09602 $\AA$ and the N-N length is $1.13465-1.23075 \AA$. All $\mathrm{C}-\mathrm{C}-\mathrm{C}$ angles range from $118^{\circ}$ to $121^{\circ}$. The $\mathrm{C}-\mathrm{C}-\mathrm{H}$ angle in the compound is $119^{\circ}-120^{\circ}$, C-C-N $116^{\circ}-120^{\circ}, \mathrm{C}-\mathrm{N}-\mathrm{N} 118^{\circ}$ and N-N-N $172^{\circ}$. There are very few differences between DFT and CAM-B3LYP values. Theoretically, calculated values of some triphenyl amine compounds can give an idea of the geometry of molecular changes.

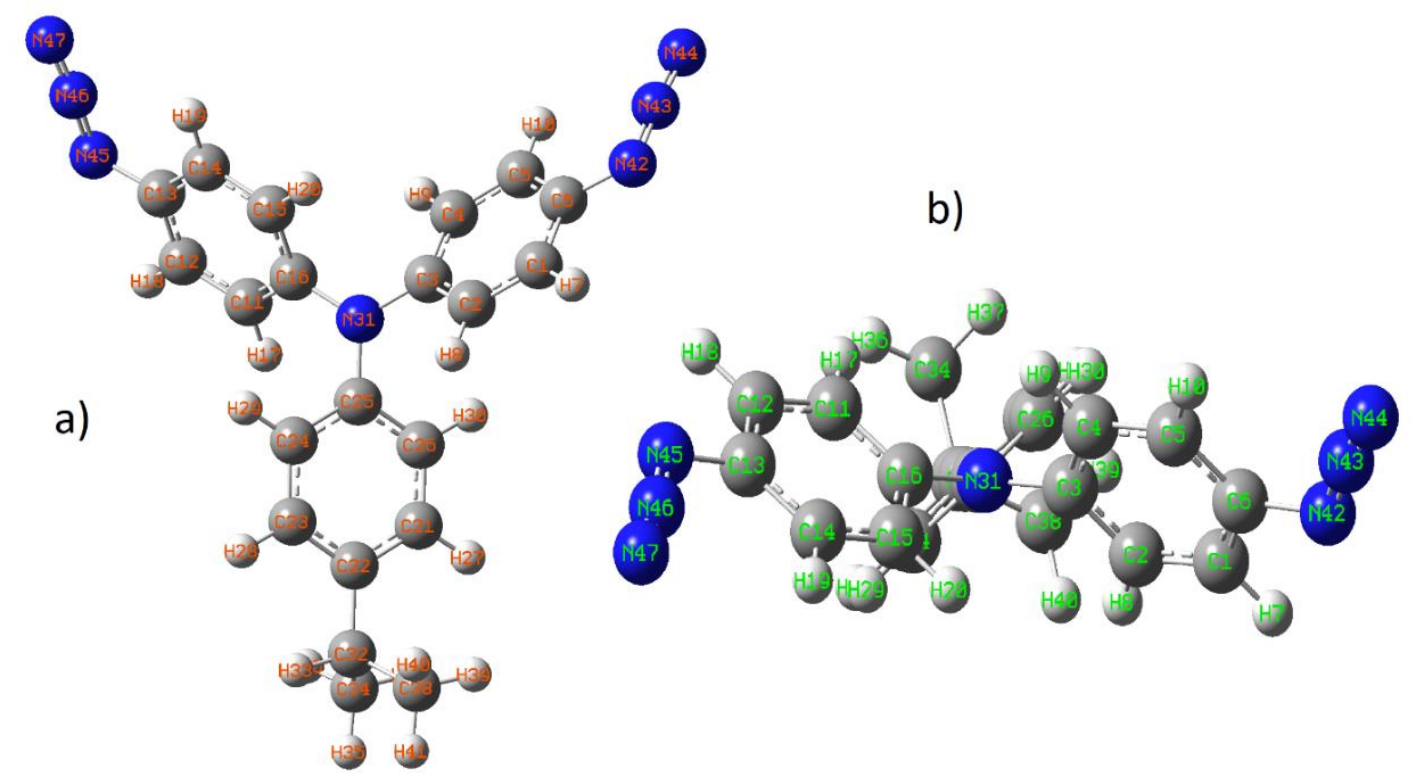

Figure 1. The three-dimensional atomic structure of IPAPA molecule is shown $(a, b)$

Table 1. Optimized geometrical parameters of IPAPA calculated at the B3LYP and CAM-B3LYP levels with $6-311++\mathrm{G}(\mathrm{d}, \mathrm{p})$ basis set

\begin{tabular}{lcclcc}
\hline Bond Lengths $(\AA)$ & B3LPY & CAM-B3LYP & Bond Angles $\left.\mathbf{(}^{(}\right)$ & B3LPY & CAM-B3LYP \\
\hline C1-C2 & 1.38735 & 1.38207 & C1-C2-C3 & 120.83823 & 120.79397 \\
C1-C6 & 1.39757 & 1.39065 & C1-C6-C5 & 119.36696 & 119.44970 \\
C1-H7 & 1.08322 & 1.08255 & C1-C6-N42 & 116.50506 & 116.55052 \\
C3-N31 & 1.41818 & 1.41386 & C6-N42-N43 & 118.82183 & 117.74133 \\
C6-N42 & 1.41977 & 1.41850 & C2-C3-C4 & 118.40597 & 118.49869 \\
C15-H20 & 1.08304 & 1.08251 & C6-C1-H7 & 119.06626 & 118.99934 \\
C14-H19 & 1.08460 & 1.08409 & C6-C5-H10 & 120.54782 & 120.64902 \\
N42-N43 & 1.23075 & 1.22677 & N42-N43-N44 & 172.98864 & 173.90410 \\
N43-N44 & 1.13465 & 1.12538 & C1-C2-H8 & 119.63556 & 119.74498 \\
C12-C13 & 1.39768 & 1.39078 & N31-C3-C2 & 120.79322 & 120.71094 \\
C12-H18 & 1.08323 & 1.08255 & N31-C3-C4 & 120.80059 & 120.79019 \\
C11-C12 & 1.38720 & 1.38192 & C3-N31-C16 & 120.19963 & 120.21968 \\
C13-N45 & 1.41983 & 1.41855 & N31-C16-C15 & 120.82049 & 120.82449 \\
N45-N46 & 1.23069 & 1.22673 & C25-C26-H30 & 119.50876 & 119.46081 \\
N46-N47 & 1.13468 & 1.12539 & C11-C12-C13 & 120.33477 & 120.28904 \\
\hline
\end{tabular}


Table 1. Optimized geometrical parameters of IPAPA calculated at the B3LYP and CAM-B3LYP levels with $6-311++\mathrm{G}(\mathrm{d}, \mathrm{p})$ basis set (continued)

\begin{tabular}{llllll}
\hline C24-H29 & 1.08355 & 1.08302 & C13-C14-H19 & 120.54168 & 120.64686 \\
C23-C24 & 1.39254 & 1.38757 & C12-C13-N45 & 116.50116 & 116.54348 \\
C21-C22 & 1.40111 & 1.39466 & C14-C13-N45 & 124.13911 & 124.00989 \\
C22-C32 & 1.52136 & 1.51587 & C13-N45-N46 & 118.82376 & 117.73957 \\
C32-C34 & 1.53993 & 1.53209 & C32-C34-H35 & 111.24436 & 110.65762 \\
C32-H33 & 1.09602 & 1.09473 & N45-N46-N47 & 172.99746 & 173.90600 \\
C32-C38 & 1.53962 & 1.53184 & C32-C34-H37 & 111.24436 & 111.12589 \\
C34-H35 & 1.09413 & 1.09283 & C26-C25-N31 & 120.64383 & 120.58889 \\
C34-H36 & 1.09296 & 1.09177 & C22-C32-C34 & 111.90613 & 111.75007 \\
C34-H37 & 1.09413 & 1.09308 & C32-C34-H36 & 111.23284 & 111.26713 \\
C38-H39 & 1.09415 & 1.09308 & C34-C32-C38 & 111.02104 & 110.94699 \\
C38-H40 & 1.09298 & 1.09179 & C32-C38-H39 & 111.31370 & 111.19158 \\
C38-H41 & 1.09413 & 1.09283 & C32-C38-H40 & 111.23292 & 111.26718 \\
C26-C30 & 1.08363 & 1.08310 & C32-C22-C21 & 121.77698 & 121.57295 \\
C21-H27 & 1.08489 & 1.08429 & C21-C26-H30 & 119.99943 & 120.08057 \\
C23-H28 & 1.08563 & 1.08487 & C25-N31-C16 & 119.92012 & 119.91356 \\
\hline
\end{tabular}

Table 1 shows optimized bond angles and bond lengths of the compound selected on the basis of DFT and CAM-B3LYP / 6-311G++ (d, p). The difference is very small and shows a good fit between the two systems.

Table 2. Optimized geometrical parameters of IPAPA calculated at the B3LYP and CAM-B3LYP levels with $6-311++\mathrm{G}(\mathrm{d}, \mathrm{p})$ basis set

\begin{tabular}{lcclcc}
\hline \multicolumn{1}{c}{ Dihedral Angles $\left(^{(}\right)$} & B3LPY & CAM-B3LYP & Dihedral Angles $\left(^{\circ}\right)$ & B3LPY & CAM-B3LYP \\
\hline C1-C2-C3-C4 & -0.19481 & -0.28253 & N42-C6-C1-H7 & 0.41423 & 0.35927 \\
C1-C6-C5-C4 & -0.30431 & -0.38371 & N45-C13-C12-H18 & 0.44360 & 0.37805 \\
C1-C6-C5-H10 & -179.34130 & -179.46581 & H7-C1-C2-H8 & -0.29476 & -0.26162 \\
C1-C6-N42-N43 & -179.65500 & -179.85042 & H9-C4-C5-H10 & -0.12829 & -0.11777 \\
C2-C3-N31-C16 & 138.32142 & 138.57564 & C24-C25-N31-C16 & -43.64461 & -43.29803 \\
C6-C1-C2-H8 & -179.36800 & -179.38684 & C22-C32-C34-H36 & -56.29107 & -56.38985 \\
C6-N42-N43-N44 & 179.44234 & 179.75639 & H33-C32-C34-H37 & -179.30505 & -179.32879 \\
C11-C12-C13-N45 & 179.54793 & 179.52180 & H27-C21-C22-C23 & -179.45792 & -179.53699 \\
C11-C12-C13-C14 & -0.47887 & -0.48801 & H35-C34-C32-H33 & -59.69236 & -59.77104 \\
N31-C3-C4-H9 & -0.40095 & -0.29943 & C22-C32-C38-H40 & 55.80680 & 56.02590 \\
C12-C13-C14-H19 & -179.36135 & -179.48246 & C22-C32-C34-H35 & -176.51710 & -176.72973 \\
C13-N45-N46-N47 & 179.50126 & 179.75265 & C22-C32-C34-H37 & 63.87021 & 63.71252 \\
\hline
\end{tabular}

Table 2 shows optimized dihedral bond angles of the compound selected on the basis of DFT and CAM-B3LYP / 6-311G++ $(\mathrm{d}, \mathrm{p})$. The difference is very small and shows a good fit between the two systems. 


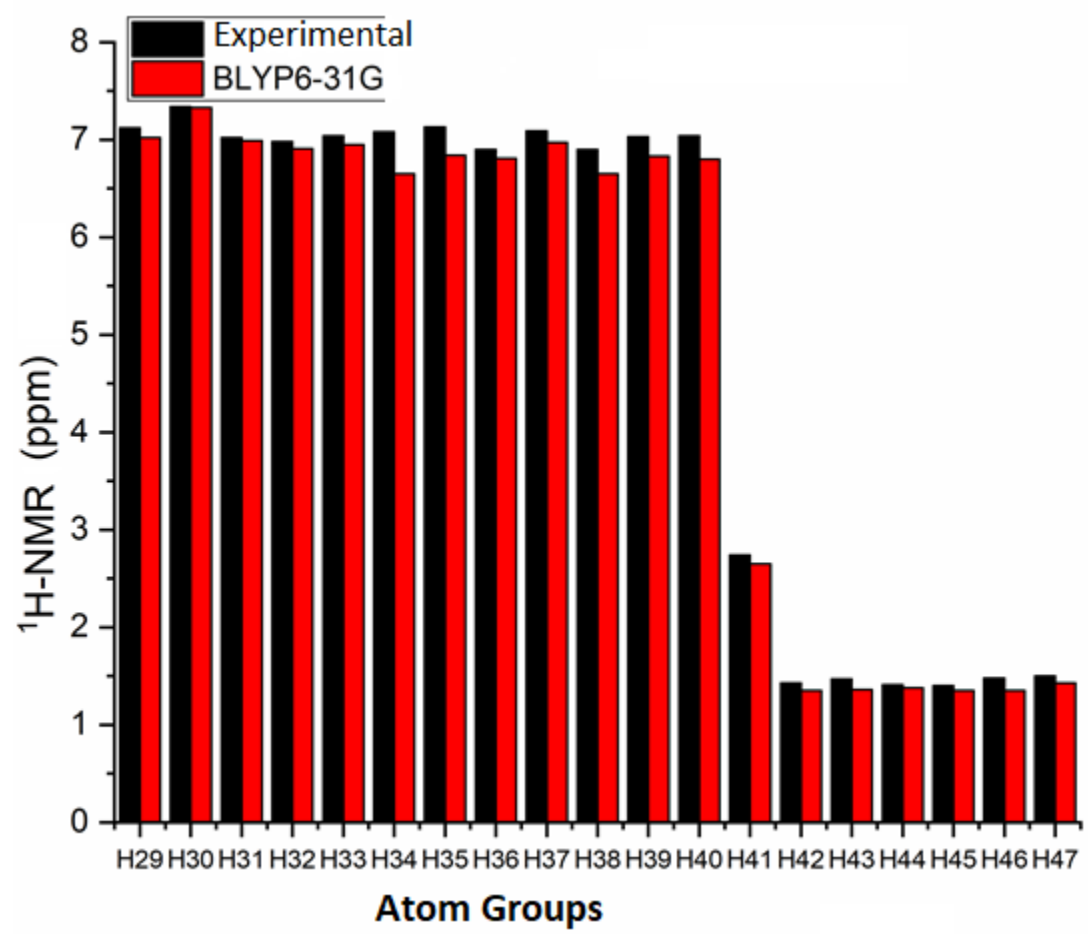

Figure 2. ${ }^{1} \mathrm{H}-\mathrm{NMR}$ Experimental and Theoretical Chemical shift graph of IPAPA molecule

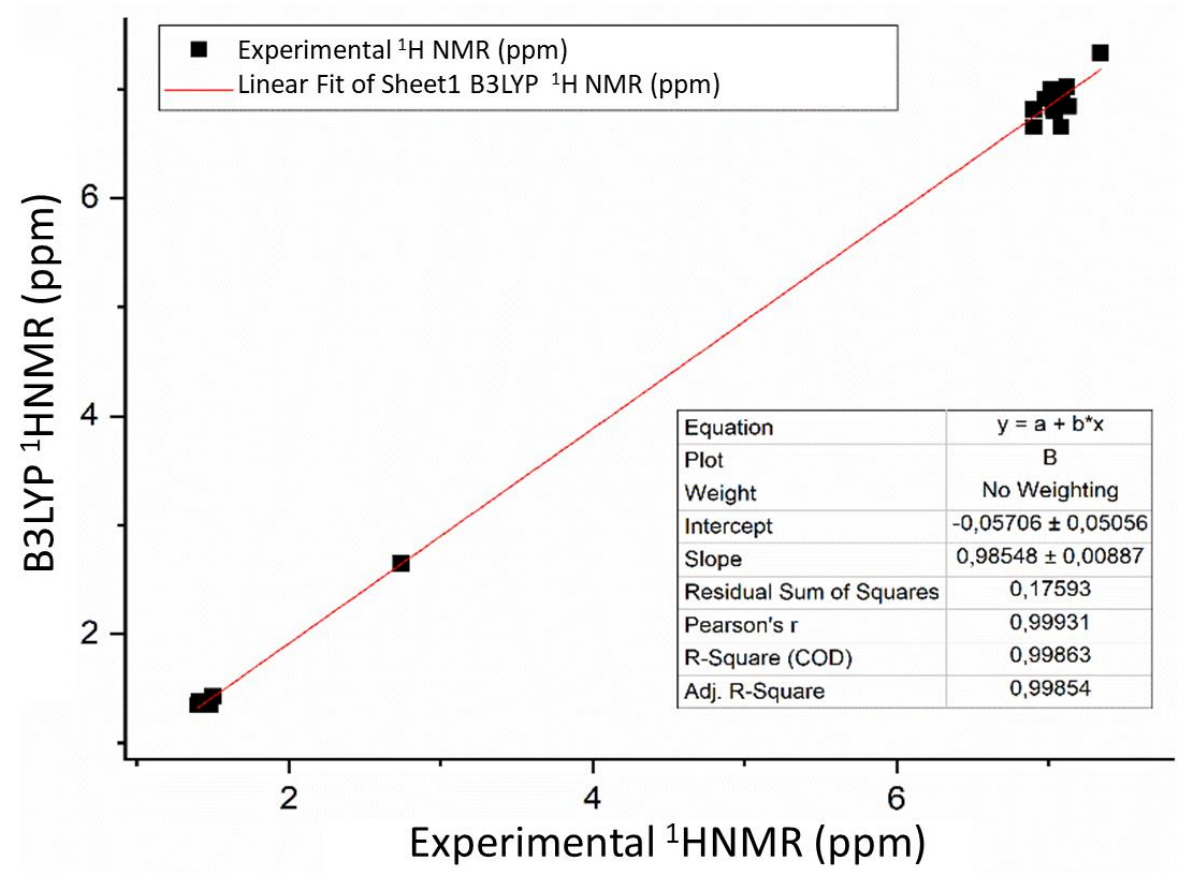

Figure 3. ${ }^{1} \mathrm{H}-\mathrm{NMR}$ Experimental and Theoretical Calculations of IPAPA molecule are shown in the graph

Regression analysis was also performed for the compatibility of the experimental and theoretical data. In the regression analysis for the compatibility of both experimental and theoretical values, experimental $_{\mathrm{NMR}}=\mathrm{a}$. theoretical $\mathrm{NMR}_{\mathrm{NM}}+\mathrm{b}$ equation was used. According to this equation, whether two variables are compatible or not, a value should be close to or equal to 1 and $b$ value should be close to or equal to 0 . 


\section{HOMO and LUMO Analysis}

HOMO shows a wide range of leading donor orbitals, while LUMO shows leading acceptor orbitals. The HOMO -1 and $\mathrm{LUMO}_{+1}$ orbitals represent the corresponding donor and acceptor levels with an energy state below and above these levels, respectively. HOMO are electrons in the outermost (highest energy) orbital that can function as an electron donor. LUMO is the innermost (lowest energy) orbital that has enough space to accept electrons and can act as an electron acceptor (Boxi et al., 2019; Damaceanu et al., 2018; Priyatha et al., 2019). Figures 4-5 are the density orbital representation of HOMO and LUMO for IPAPA. E $\mathrm{LUMO}_{+1}$ and $\mathrm{E}_{\mathrm{HOMO}-1}$ graphs of the compound were also obtained. E $_{\text {LUMO }}-1,4776 \mathrm{eV}-\mathrm{E}_{\text {HOMO }}-5,3300 \mathrm{eV}$ for the B3LYP method and $\mathrm{E}_{\mathrm{LUMO}}-0.2255 \mathrm{eV}-\mathrm{E}_{\mathrm{HOMO}}-6,5376$ $\mathrm{eV}$ for the CAM-B3LYP method were calculated from the figure. $\mathrm{E}_{\mathrm{LUMO}+1}-1,3935 \mathrm{eV}-\mathrm{E}_{\mathrm{HOMO}-1}-6,6647$ $\mathrm{eV}$ for B3LYP method and $\mathrm{E}_{\mathrm{LUMO}}+1-0.01959 \mathrm{eV}-\mathrm{E}_{\mathrm{HOMO}-1}-8.0250 \mathrm{eV}$ for CAM-B3LYP method were calculated. The calculated highest filled molecular orbital (HOMO) and lowest empty molecular orbital (LUMO) energies also confirm that charge transfer occurs within the molecule(Najare et al., 2019). The energy difference between the HOMO and LUMO energies, called the energy gap, helps the chemical reactivity and the kinetic stability of the molecule. Polarization shows the reactive indexes of a molecule with hardness, electronegativity and a small boundary orbital space. Table 3 shows the chemical reactivity indices.
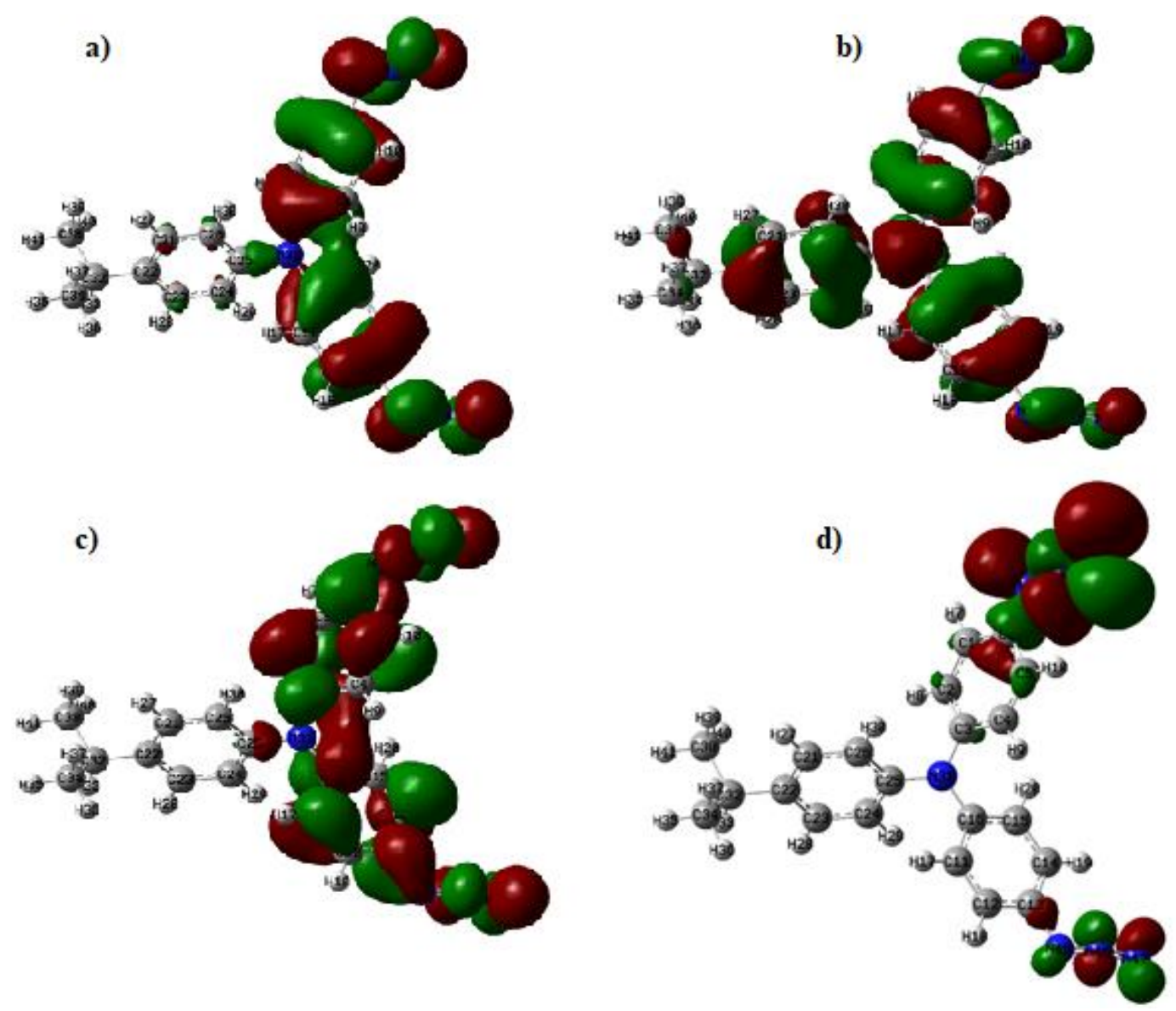

Figure 4. IPAPA molecule; a) DFTнмо-1, b) DFThомо, c) DFT Dumo, d) DFT $_{\text {Lumo +1 atomic }}$ orbital composition of a molecule 
Table 3. Comparison of molecular properties of HOMO, LUMO, Energy gaps (HOMO - LUMO) and related IPAPA $(\mathrm{au})$ using the DFT-CAM/B3LYP/6-311++G(d,p) method

\begin{tabular}{|c|c|c|}
\hline Molecular Energy & B3LYP & CAM-B3LYP \\
\hline ELuMO & -1.4776 & -0.2255 \\
\hline $\mathrm{E}_{\text {Hомо }}$ & -5.3300 & -6.5376 \\
\hline Energy deficit $(\Delta)$ & -3.8524 & -6.3121 \\
\hline Ionization Potential (I) & 5.3300 & 6.5376 \\
\hline Electron Relevance $(A)$ & 1.4776 & 0.2255 \\
\hline Global Hardness $(\eta)$ & -1.9262 & -3.1560 \\
\hline Global Softness $(s)$ & -0.9631 & -1.5780 \\
\hline Chemical potential $(\mu)$ & 3.4038 & 3.3815 \\
\hline Electronegativity $(\chi)$ & 1.2388 & 0.6127 \\
\hline Global Electrophilicity $(\omega)$ & -6.0148 & $-1,1811$ \\
\hline
\end{tabular}

Dipole moment is an important feature of the energy related to the electric field applied in the molecule. The dipole moment consists of intermolecular interactions involving the Van der Waals type dipole-dipole forces and generates strong intermolecular attraction. The dipole moment $(\mu)$ values of IPAPA molecule were calculated as 3.3628 Debye for B3LYP and 3.0239 Debye for CAM-B3LYP, respectively. Both methods show that the molecule has nonlinear properties.
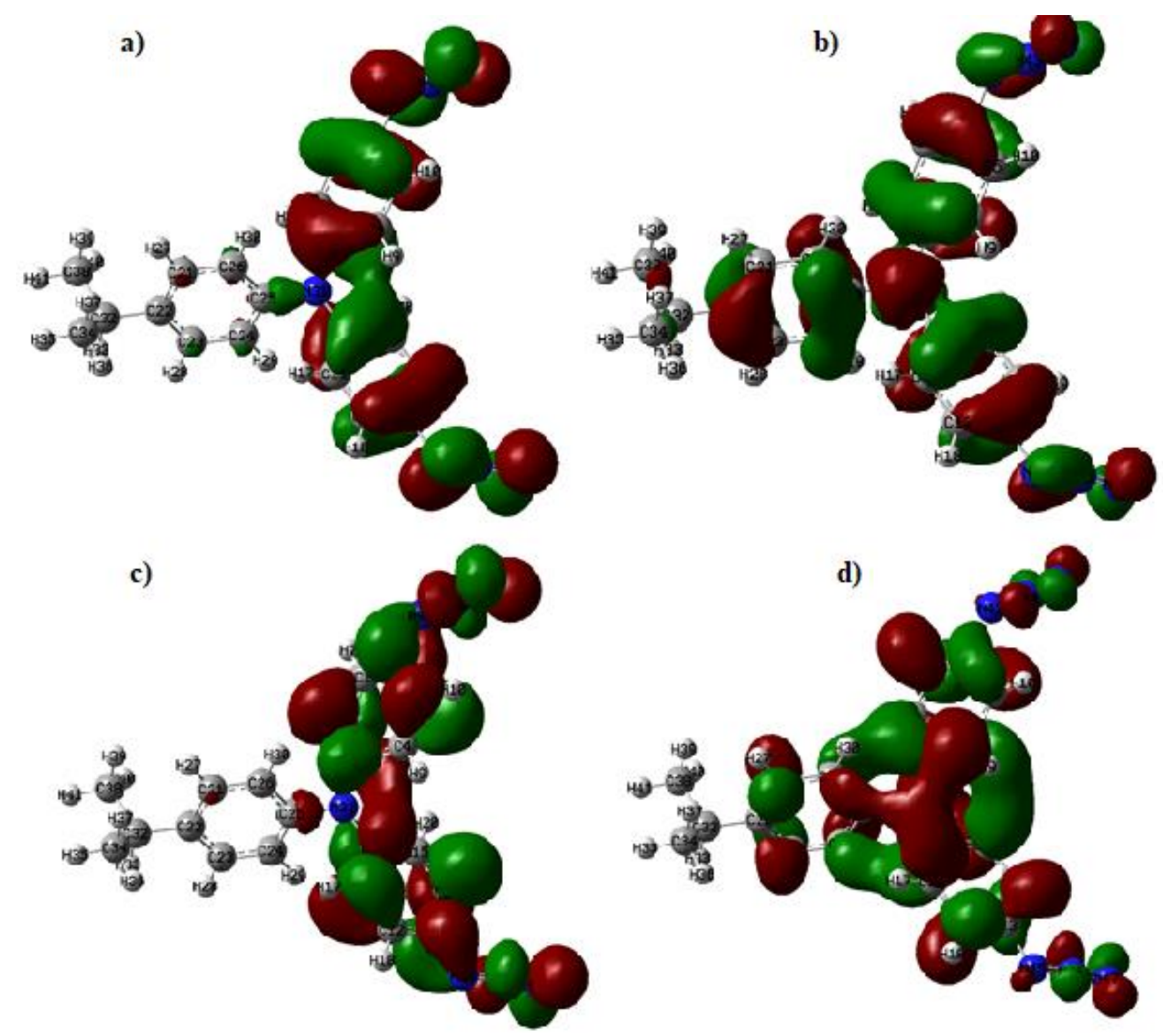

Figure 5. IPAPA molecule; a) CAM номо-1, b) CAMномо, c) CAMlumo, d) CAMLumo + 1 atomic orbital composition of a molecule 
The parameters calculated in Table 5 show the electronic dipole moment and the total dipole moment. It can be calculated using the following equation.

$<\alpha>=1 / 3\left(\alpha_{\mathrm{xx}}+\alpha_{\mathrm{yy}}+\alpha_{\mathrm{zz}}\right)$

$<\beta_{\text {tot }}>=\left[\left(\beta_{\mathrm{xxx}}+\beta_{\mathrm{xyy}}+\beta \mathrm{xzz}\right)^{2}+\left(\beta_{\mathrm{yyy}}+\beta_{\mathrm{yzz}}+\beta \mathrm{yxx}\right)^{2}+\left(\beta_{\mathrm{zzz}}+\beta_{\mathrm{zxx}}+\beta z y \mathrm{y}\right)^{2}\right]^{1 / 2}$

Table 4. Basic set of CAM with DFT B3LYP / 6-311G++ (d, p), calculated dipole moments of electricity (Debye), (au) polarisability, $\beta$ components and $\beta$ tot 4-isopropyl-N, N-Bis (4- Azidophenyl) Aniline value

\begin{tabular}{|c|c|c|c|c|c|c|c|c|}
\hline Parameters & B3LYP & $\begin{array}{l}\text { CAM- } \\
\text { B3LYP }\end{array}$ & Parameters & B3LYP & $\begin{array}{l}\text { CAM- } \\
\text { B3LYP }\end{array}$ & Parameters & B3LYP & $\begin{array}{l}\text { CAM- } \\
\text { B3LYP }\end{array}$ \\
\hline$\mu_{\mathrm{x}}$ & -3.3384 & -2.9997 & $\alpha_{\mathrm{xx}}$ & -168.4820 & $\begin{array}{c}- \\
166.7202\end{array}$ & $\beta \mathrm{xxx}$ & $\begin{array}{c}- \\
129.0892\end{array}$ & $\begin{array}{c}- \\
116.885 \\
0\end{array}$ \\
\hline$\mu_{\mathrm{y}}$ & -0.3968 & -0.3744 & $\alpha_{\mathrm{yy}}$ & -184.6869 & $\begin{array}{c}- \\
183.1794\end{array}$ & $\beta_{\mathrm{XXY}}$ & 9.8159 & 8.0053 \\
\hline$\mu_{\mathrm{z}}$ & -0.0794 & -0.0742 & $\alpha_{\mathrm{zz}}$ & -163.3488 & $\begin{array}{c}- \\
163.6825\end{array}$ & $\beta_{\mathrm{XYY}}$ & $\begin{array}{c}- \\
110.2374\end{array}$ & 96.6208 \\
\hline$\mu_{(\mathrm{D})}$ & 3.3628 & 3.0239 & $\begin{array}{c}\alpha \alpha_{\mathrm{XY}} \\
\alpha \alpha_{\mathrm{XZ}} \\
\alpha \mathrm{YZ} \\
\alpha(\mathrm{au})\end{array}$ & $\begin{array}{c}2.4855 \\
0.4174 \\
-1.1425 \\
-172,1725\end{array}$ & $\begin{array}{c}2.5158 \\
0.3699 \\
-0.3026 \\
- \\
171,1940\end{array}$ & $\begin{array}{l}\beta_{\mathrm{YYY}} \\
\beta_{\mathrm{XXZ}} \\
\beta_{\mathrm{XYZ}} \\
\beta_{\mathrm{YYZ}}\end{array}$ & $\begin{array}{c}-37.5913 \\
0.1053 \\
-21.4529 \\
-5.8448\end{array}$ & $\begin{array}{c}-34.0256 \\
-0.3011 \\
-18.6032 \\
-5.0772\end{array}$ \\
\hline & & & & & & $\begin{array}{c}\beta \text { xzZ } \\
\beta \text { yzz } \\
\beta \text { zzz } \\
\beta(\mathrm{esu})\end{array}$ & $\begin{array}{c}0.7633 \\
-0.2082 \\
1.0690 \\
2.4 \times 10^{-32}\end{array}$ & $\begin{array}{c}0.2473 \\
-0.3079 \\
-1.1016 \\
3.3 \times 10^{-32}\end{array}$ \\
\hline
\end{tabular}

\section{Molecular Electrostatic Potential Surface (MEPS)}

The molecular electrostatic potential surface (MEPS) are useful amounts to show charge distributions of molecules and visualize variable charged molecule regions and is plotted for the IPAPA molecule. Molecular electrostatic potential (MEPS) mapping plays an important role in investigating many features of the molecular structure. MEPS is widely used as a reactivity map to understand the hydrogen bonding interactions on organic molecules as well as electrophilic and nucleophilic reactions. Some of the molecule with negative electrostatic potential is sensitive to electrophilic attacks (Dwivedi et al., 2015; Srivastava et al., 2015).Different values of the electrostatic potential on the surface are shown in different colors (blue to red). The strongest attraction is represented by the positive (blue color) region, while the strongest repulsion is represented by the negative (red color) region. The green color indicates neutral electrostatic potential (Jayashree et al., 2019). Negative (red, orange and yellow) regions of MEPS show electrophilic reactivity and positive (blue color) ones belong to the nucleophilic reactivity region.

In this study, molecular electrostatic potential (MEPS) was coupled with 4 IPAPA maps as shown in Figure 6-7. In the case of IPAPA molecule, there are negative regions of the nitrogen atoms characterized by red in the MEPS map. IPAPA relatively large region around the nitrogen atoms of the aniline molecule represents the most negative potential region (dark red) and is suitable for electrophilic interaction. The hydrogen atom carries the maximum strength of the positive charge (dark blue). The aromatic ring region shows an almost neutral potential, most of which is represented by green colors. 


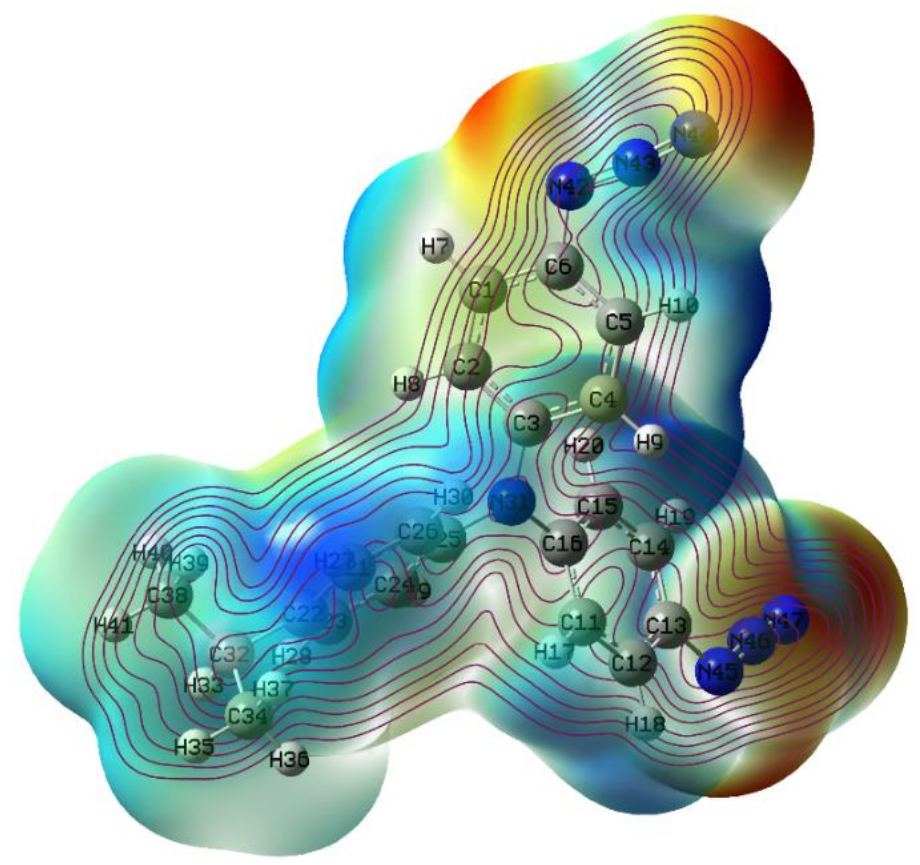

Figure 6. Molecular electrostatic potential of IPAPA

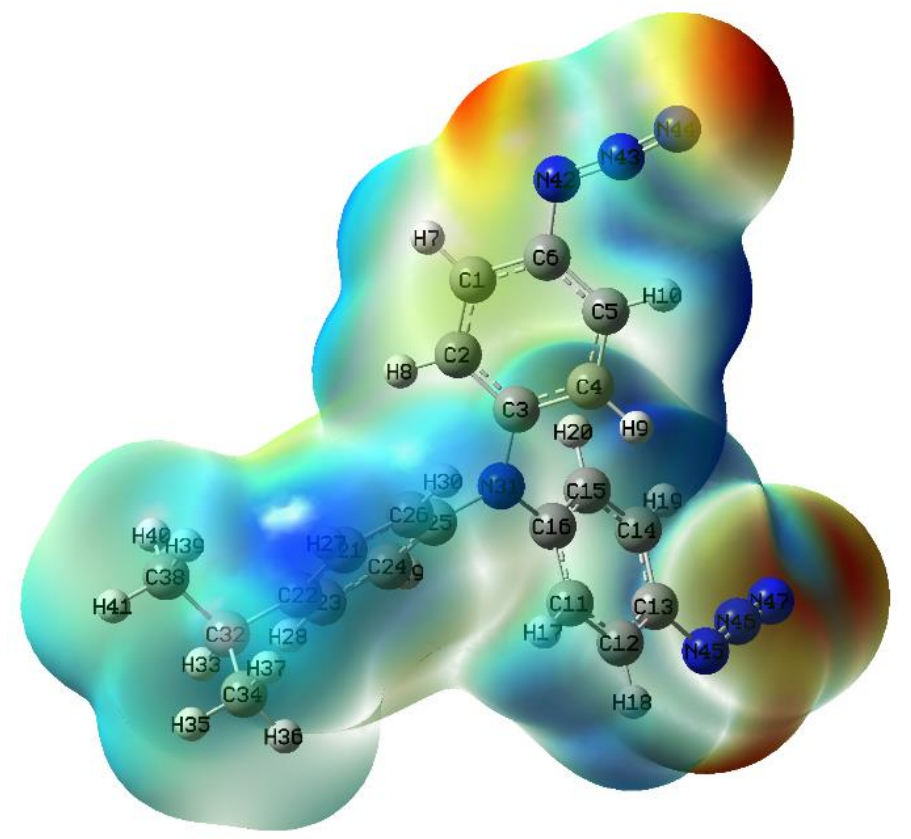

Figure 7. Molecular electrostatic potential of IPAPA

\section{Mulliken Atomic Charges}

The atomic charges play an important role in the application of quantum chemical calculations of molecular system because of the atomic charges affect dipole moment, polarizability, electronic structure, vibrational spectra and more properties for a molecular system (Téllez Soto et al., 2013). The charge distribution in the atom indicates the formation of donor and acceptor pairs, including charge transfer within the molecule (Priya et al., 2019). Mulliken atom was calculated using the DFT and CAM methods in the base set B3LYP / 6-311G++ $(d, p)$. The data obtained are presented in Figure 8-9 and Table 5. The distribution of the mullikene charge of the nitrogen atom $\mathrm{N}$ attached to the aromatic ring is N31 (0.852537) - (0.793107), N42 (0.355902) - (-0.033063), N43 (0.046818) - (-0.029280), N44 ($0.258854)-(-) 0.278103), \mathrm{N} 45(0.363991)-(0.448551), \mathrm{N} 46(0.049169)-(-0.033063)$, and N47 (- 
$0.270415)-(-0.283405)$ indicate a negative charge. The charge value of the $\mathrm{H}$ atom attached to the aromatic ring has a positive charge. Some $\mathrm{C}$ atoms were observed to be positive and others negative.

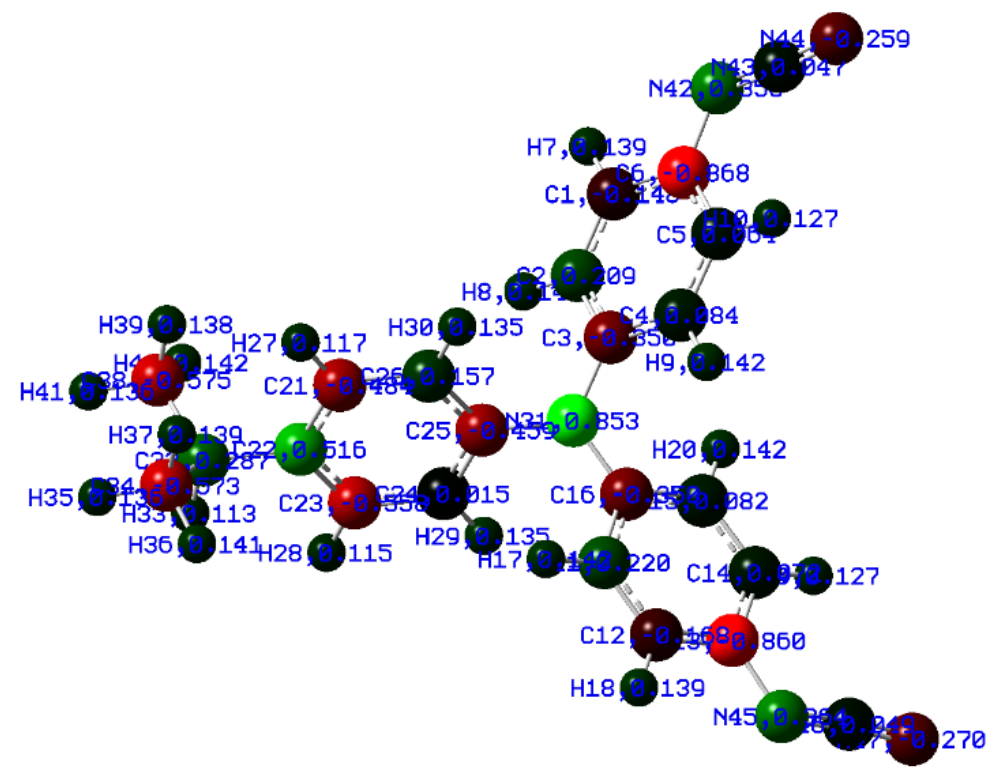

Figure 8. Mulliken atomic charges of IPAPA

Table 5. Mulliken atomic charges were calculated with B3LYP and CAM B3LYP / 6-311G++ (d,p)

\begin{tabular}{lccccc}
\hline & B3LYP & CAM-B3LYP & & B3LYP & CAM-B3LYP \\
\hline C1 & -0.147582 & -0.012631 & N43 & 0.046818 & -0.029280 \\
C2 & 0.209087 & 0.079071 & N44 & -0.258854 & -0.278103 \\
C3 & 0.349759 & -0.244121 & N45 & 0.363991 & 0.448551 \\
C4 & 0.083747 & 0.037754 & N46 & 0.049169 & -0.033063 \\
C5 & 0.064443 & 0.055930 & H7 & 0.138957 & 0.149517 \\
C6 & -0.868131 & -0.876341 & H8 & 0.142649 & 0.154376 \\
C11 & 0.219670 & 0.124314 & H9 & 0.141830 & 0.152190 \\
C12 & -0.168464 & -0.047091 & H10 & 0.127499 & 0.134440 \\
C13 & -0.860012 & -0.889883 & H17 & 0.142492 & 0.154072 \\
C14 & 0.072342 & 0.058752 & H18 & 0.138727 & 0.149690 \\
C15 & 0.081539 & 0.033483 & H19 & 0.127460 & 0.134389 \\
C16 & -0.350165 & -0.262252 & H20 & 0.142480 & 0.152670 \\
C21 & -0.483687 & -0.277844 & H27 & 0.117111 & 0.126677 \\
C22 & 0.516294 & 0.318152 & H28 & 0.115338 & 0.124321 \\
C23 & -0.558061 & -0.353494 & H29 & 0.134860 & 0.145142 \\
C24 & 0.014625 & -0.111687 & H30 & 0.134574 & 0.144710 \\
C25 & -0.458647 & -0.381255 & H33 & 0.112695 & 0.120309 \\
C26 & 0.157161 & -0.070516 & H35 & 0.135756 & 0.138059 \\
C32 & 0.286690 & 0.187423 & H36 & 0.140764 & 0.143610 \\
C34 & -0.572865 & -0.557127 & H37 & 0.138521 & 0.140009 \\
C38 & -0.575038 & -0.553779 & H39 & 0.138056 & 0.139249 \\
N31 & 0.852537 & 0.793107 & H40 & 0.142051 & 0.144579 \\
N42 & 0.355902 & 0.439243 & H41 & 0.135844 & 0.138082 \\
\hline
\end{tabular}




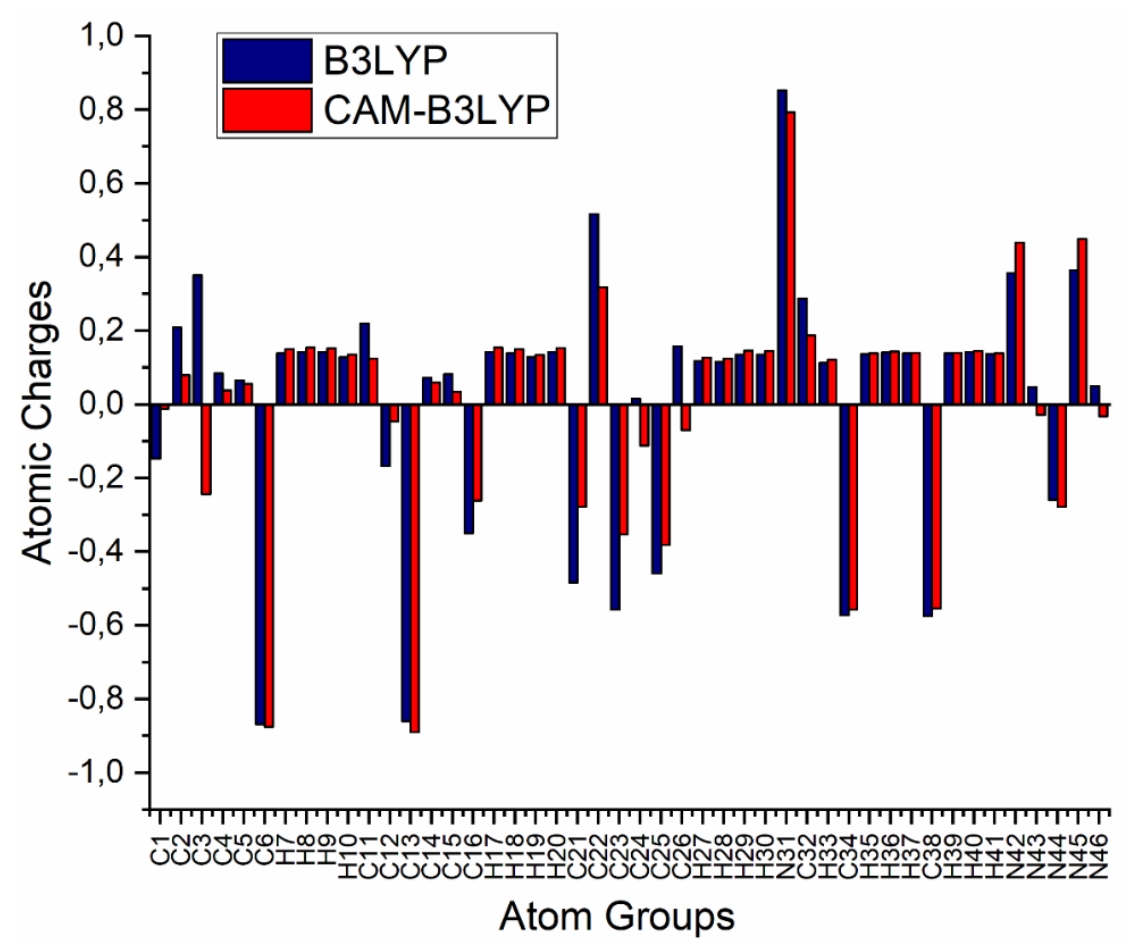

Figure 9. Comparison of IPAPA Mulliken atomic charges by two methods

\section{CONCLUSION}

In general, good agreement was obtained between experimental results synthesized in laboratory and theoretical results. In this case, it showed the reliability of the theoretical method used and good results were obtained with 6-31G ++ $(\mathrm{d}, \mathrm{p})$ basic set of B3LYP/CAM-B3LYP method for the theoretical calculation of IPAPA. Molecules were drawn in the ChemBioDraw program and transferred to Gaussian 09 program and the proton NMR data were very close to the experimental data. Thus, by considering these data for future studies, it will provide important facilities for the synthesis of molecules by minimizing the chemical consumption of the molecules to be synthesized in the future and making necessary predictions. As a result, the synthesized IPAPA were characterized by various theoretical methods and their structures were determined.

\section{REFERENCES}

Bourass M, El Alamy, A, \& Bouachrine, M. (2019). Structural and photophysical studies of triphenylamine-based nonlinear optical dyes: effects of $\pi$-linker moieties on the D- $\pi$-A structure. Comptes Rendus Chimie, 22(5), 373-385.

Boxi S, Jana, D, \& Ghorai, BK. (2019). Synthesis and optical properties of bipolar quinoxaline-triphenylamine based stilbene compounds. Optical Materials: X, 1, 100013.

Boyd RJ. (2019). Theoretical and Computational Chemistry. In Reference Module in Chemistry, Molecular Sciences and Chemical Engineering: Elsevier.

Damaceanu M-D, Constantin, C-P, Bruma, M, \& Begunov, RS. (2018). The photo-optical and electrochemical activity promoted by trifluoromethyl-substituted and ortho-catenated triphenylamine core in poly(ether-imide)s. Polymer, $151,34-46$.

Duan L, Chen, Y, Zong, X, Liu, R, Sun, Z, Liang, M, Wu, Q, \& Xue, S. (2019). Facile synthesis of triphenylamine-based hole-transporting materials for planar perovskite solar cells. Journal of Power Sources, 435, 226767.

Dwivedi A, Srivastava, AK, \& Bajpai, A. (2015). Vibrational spectra, HOMO, LUMO, MESP surfaces and reactivity descriptors of amylamine and its isomers: A DFT study. Spectrochimica Acta Part A: Molecular and Biomolecular Spectroscopy, 149, 343-351.

Gu D, Yang, G, He, Y, Qi, B, Wang, G, \& Su, Z. (2009). Triphenylamine-based pH chemosensor: Synthesis, crystal structure, photophysical properties and computational studies. Synthetic Metals, 159(23), 2497-2501. 
Jayashree A, Narayana, B, Kumar, SM, Raghi, KR, Sarojini, BK, \& Kumar, TKM. (2019). Synthesis, X-ray crystal structure, Hirshfeld surface analysis, DFT, MESP and molecular docking studies of 2-(4-bromophenyl)-1-(3-fluoro-4methylphenyl)-4,5-diphenyl-1H-imidazole. Chemical Data Collections, 21, 100237.

M. J. Frisch GWT, H. B. Schlegel, G. E. Scuseria, M. A. Robb, J. R. Cheeseman, G. Scalmani, V. Barone, G. A. Petersson, H. Nakatsuji, X. Li, M. Caricato, A. Marenich, J. Bloino, B. G. Janesko, R. Gomperts, B. Mennucci, H. P. Hratchian, J. V. Ortiz, A. F. Izmaylov, J. L. Sonnenberg, D. Williams-Young, F. Ding, F. Lipparini, F. Egidi, J. Goings, B. Peng, A. Petrone, T. Henderson, D. Ranasinghe, V. G. Zakrzewski, J. Gao, N. Rega, G. Zheng, W. Liang, M. Hada, M. Ehara, K. Toyota, R. Fukuda, J. Hasegawa, M. Ishida, T. Nakajima, Y. Honda, O. Kitao, H. Nakai, T. Vreven, K. Throssell, J. A. Montgomery, Jr., J. E. Peralta, F. Ogliaro, M. Bearpark, J. J. Heyd, E. Brothers, K. N. Kudin, V. N. Staroverov, T. Keith, R. Kobayashi, J. Normand, K. Raghavachari, A. Rendell, J. C. Burant, S. S. Iyengar, J. Tomasi, M. Cossi, J. M. Millam, M. Klene, C. Adamo, R. Cammi, J. W. Ochterski, R. L. Martin, K. Morokuma, O. Farkas, J. B. Foresman, and D. J. Fox. (2016). Gaussian 09, Revision A.02, Gaussian, Inc., Wallingford CT,

Najare MS, Patil, MK, Nadaf, AA, Mantur, S, Inamdar, SR, \& Khazi, IAM. (2019). Synthesis, characterization and photophysical properties of a new class of pyrene substituted 1,3,4-oxadiazole derivatives. Optical Materials, 88, 256265.

Priya MK, Revathi, BK, Renuka, V, Sathya, S, \& Asirvatham, PS. (2019). Molecular Structure, Spectroscopic (FT-IR, FTRaman, 13C and 1H NMR) Analysis, HOMO-LUMO Energies, Mulliken, MEP and Thermal Properties of New Chalcone Derivative by DFT Calculation. Materials Today: Proceedings, 8, 37-46.

Priyatha E, Sathishkumar, C, Palanisami, N, Venkatachalam, S, \& Venkateswaran, R. (2019). Conjugated hole-transport molecules based on triphenylamine and aminoflourene: Synthesis, structural, solvatochromic and electrochemical properties. Journal of Molecular Structure, 1179, 145-153.

Qian X, Lan, X, Yan, R, He, Y, Huang, J, \& Hou, L. (2017). T-shaped (D)2-A- $\pi-A$ type sensitizers incorporating indoloquinoxaline and triphenylamine for organic dye-sensitized solar cells. Electrochimica Acta, 232, 377-386.

Sęk D, Kotowicz, S, Kula, S, Siwy, M, Szłapa-Kula, A, Małecki, JG, Maćkowski, S, \& Schab-Balcerzak, E. (2019). Thermal, spectroscopic, electrochemical, and electroluminescent characterization of malononitrile derivatives with triphenylamine structure. Spectrochimica Acta Part A: Molecular and Biomolecular Spectroscopy, 210, 136-147.

Srivastava AK, Pandey, AK, Jain, S, \& Misra, N. (2015). FT-IR spectroscopy, intra-molecular C-H -.OO interactions, HOMO, LUMO, MESP analysis and biological activity of two natural products, triclisine and rufescine: DFT and QTAIM approaches. Spectrochimica Acta Part A: Molecular and Biomolecular Spectroscopy, 136, 682-689.

Steponaitis M, Komskis, R, Kamarauskas, E, Malinauskas, T, Jursenas, S, \& Getautis, V. (2019). Investigation of photophysical properties of triphenylamine phenylethenyl derivatives containing tertiary amine groups. Dyes and Pigments, 166, 122-129.

Téllez Soto CA, Costa, AC, Ramos, JM, Vieira, LS, Rost, NCV, Versiane, O, Rangel, JL, Mondragón, MA, Raniero, L, \& Martin, AA. (2013). Surface enhanced Raman scattering, electronic spectrum, natural bond orbital, and mulliken charge distribution in the normal modes of diethyldithiocarbamate copper (II) complex, [Cu(DDTC)2]. Spectrochimica Acta Part A: Molecular and Biomolecular Spectroscopy, 116, 546-555.

Weng D, Shi, Y, Zheng, J, \& Xu, C. (2016). High performance black-to-transmissive electrochromic device with panchromatic absorption based on TiO2-supported viologen and triphenylamine derivatives. Organic Electronics, 34, 139-145.

Yadav SB, Kothavale, S, \& Sekar, N. (2019). Triphenylamine and N-phenyl carbazole-based coumarin derivatives: Synthesis, solvatochromism, acidochromism, linear and nonlinear optical properties. Journal of Photochemistry and Photobiology A: Chemistry, 382, 111937.

Yadav SB, Sonvane, SS, \& Sekar, N. (2020). Novel blue-green emitting NLOphoric triphenylamine-imidazole based donor$\pi$-acceptor compound: Solvatochromism, DFT, TD-DFT and non-linear optical studies. Spectrochimica Acta Part A: Molecular and Biomolecular Spectroscopy, 224, 117421.

Yoosuf M, Pradhan, SC, Soman, S, \& Gopidas, KR. (2019). Triple bond rigidified anthracene-triphenylamine sensitizers for dye-sensitized solar cells. Solar Energy, 188, 55-65. 